\title{
Quality of Banana cv. Grand Nain Influenced by Nitrogen and Bio-fertilizers
}

\author{
P. R. Patel, B. N. Patel*, Devraj and S. J. Patil \\ Department of Fruit Science, ASPEE College of Horticulture and Forestry, Navsari \\ Agricultural University, Navsari- 396450 Gujarat, India \\ *Corresponding author
}

\section{A B S T R A C T}

K e y w o r d s
Ascorbic acid,
Azospirillum,
Azotobacter, Pulp:
peel ratio,
Rhizobium, RDN,
Shelf life, Sugar,
Sugar: pulp ratio,
Titrable acidity,
TSS
Article Info
Accepted:
04 November 2020
Available Online:
10 December 2020

\section{Introduction}

Banana is an important fruit crop of tropics. Banana is an antique fruit crop of the world also known as 'Apple of the Paradise' and botanically named as Musa spp. India is the largest banana producing and consuming nation in the world contributing about 25.71 $\%$ to the overall global production. Major banana growing states of India are Andhra Pradesh, Assam, Bihar, Gujarat, Karnataka, Kerala, Madhya Pradesh, Maharashtra, Orissa and West-Bengal. Gujarat ranks at sixth
Banana is a well-established fruit crop of Gujarat region and more specifically cultivar Grand Nain is well adopted due to its good yield potential and quality parameters. Banana is nutrient loving crop so application of nitrogen and bio-fertilizers plays significant role in quality improvement of crop. By considering this fact presented experiment "Quality of banana cv. Grand Nain influenced by nitrogen and biofertilizers" was taken during 2018-19. The experiment was designed under Randomized blocked design with factorial concept. There were two factors i.e. Factor - 1: Nitrogen level ( $\mathrm{D}_{1}-100 \%$ RDN, $\mathrm{D}_{2}-80 \%$ RDN, $\left.\mathrm{D}_{3}-60 \% \mathrm{RDN}\right)$, Factor - 2: Bio-fertilizers [B $\mathrm{B}_{1}$ - Azotobacter $(20 \mathrm{ml} / \mathrm{plant}), \mathrm{B}_{2}$ - Azospirillum $(20 \mathrm{ml} / \mathrm{plant}), \mathrm{B}_{3}$ Rhizobium (20 ml/plant), $\mathrm{B}_{4}-50 \%$ of $\mathrm{B} 1+50 \%$ of $\mathrm{B}_{2}+50 \%$ of $\mathrm{B}_{3}, \mathrm{~B}_{5}-$ No biofertilizer (Control)]. Effects of these treatment were observed for quality parameters like total soluble solids, titrable acidity, ascorbic acid, reducing sugar, non reducing sugar, total sugar, sugar: acid ratio, pulp: peel ratio and shelf life. Although there are no significant effects of interaction on any quality parameters but individual effects of both the factor were observed significantly positive on reducing sugar, total sugar, sugar: acid ratio, pulp: peel ratio and shelf life.

position in area (433.79 thousand ha) and is at fourth position in production (9227.72 thousand MT) as well as productivity (65.63 t/ha) (Anon., 2018).

Banana is a heavy feeder of nutrients and thus need balanced nutrition for optimum growth and fruit production. This crop is well responds to split application of nutrients. The choice and dosage of nutrients, time, mode and frequency of application vary depending on the cultivars, initial soil fertility, production system and agro climatic 
conditions. Bio-fertilizers play a very significant role in improving quality by fixing atmospheric nitrogen both in association with and without plant roots. However, information on the combined use of inorganic fertilizers and bio-fertilizers is limited. There is a scarcity of information on the integrated nutrient management in banana crop. Generation of such information is of immense importance for switching over better fertilizer technology and to produce export quality bananas. In view of the paucity of information pertaining to the integrated nutrient management in banana under high density plantation, the present study on "Quality of banana cv. Grand Nain influenced by nitrogen and bio-fertilizers" was designed.

\section{Materials and Methods}

The experiment was conducted on "Quality of banana cv. Grand Nain influenced by nitrogen and bio-fertilizers" during the year 2018-19 at Regional Horticultural Research Station, ASPEE College of Horticulture and Forestry, Navsari Agricultural University, Navsari. According to the agro-climatic situation, Navsari falls under South Gujarat Heavy Rainfall Zone-I and Agro Ecological Situation-III (AES-III). The climate of this zone is tropical, characterized by humid and warm monsoon with heavy rainfall, moderately cold winter and fairly hot and humid summer. The soil of south Gujarat is locally known as 'black cotton soil'. As per the soil taxonomy, the experimental soil belongs to order Inceptisols, sub-order Ochrepts, great soil group Vertic Ustochrepts under the soil series of Jalapore. The soil is very deep, rich in organic matter and potash, which was classified earlier as "Deep Black Soil". Planting was carried out in July, 2018 with healthy tissue cultured plants of banana cv. Grand Nain procured from Tissue Culture Laboratory, Department of Biotechnology, ACHF, NAU, Navsari, Gujarat was used.

\section{Treatment details}

The experiment was portrayed in Randomized blocked design with factorial concept along with two factors which are given in detail below:

\begin{tabular}{|c|c|}
\hline \multicolumn{2}{|c|}{ Factor-A Nitrogen level } \\
\hline $\mathbf{D}_{1}$ & $100 \%$ RDN \\
\hline$D_{2}:$ & $80 \% \mathrm{RDN}$ \\
\hline$D_{3}:$ & $60 \% \mathrm{RDN}$ \\
\hline \multicolumn{2}{|c|}{ Factor-B Bio-fertilizers } \\
\hline $\mathbf{B}_{1}:$ & Azotobacter $(20 \mathrm{ml} / \mathrm{plant})$ \\
\hline $\mathbf{B}_{2}$ : & Azospirillum (20 ml/plant) \\
\hline $\mathbf{B}_{3}:$ & Rhizobium (20 ml/plant) \\
\hline $\mathbf{B}_{4}:$ & $50 \%$ of $\mathrm{B}_{1}+50 \%$ of $\mathrm{B}_{2}+50 \%$ of $\mathrm{B}_{3}$ \\
\hline$B_{5}:$ & No bio-fertilizer (Control) \\
\hline
\end{tabular}

\section{Quality parameters}

Total soluble solids in a sample were recorded by using a digital hand refractometer PAL-1 (Atago, Japan). For this purpose, four fruits were selected randomly from each treatment of the net plot. The juice was extracted with help of pieces of muslin cloth and measured by hand refractometer. Method described by Ranganna (1986) was adopted for estimation of titrable acidity, ascorbic acid, reducing sugar and total sugar. The value of nonreducing sugars was recorded by subtracting the value of reducing sugars from total sugars. Sugar: acid ratio was computed by dividing total sugars by acidity. For pulp: peel ratio, fully ripe fruits were weighed and peeled. The peel was weighed and pulp weight was arrived at by calculating the difference between the two and ratio was measured. The shelf life of fruits was noted by keeping the fruits at room temperature and recorded the day's taken from harvesting to the appearance of any spoilage symptoms or discolouration.

\section{Results and Discussion}

The results regarding effect of different levels of nitrogen and bio-fertilizers on 
quality parameters i.e. TSS, titrable acidity, ascorbic acid, reducing sugar, non reducing sugar, total sugar, sugar: acid ratio pulp: peel ratio and shelf life were demonstrated in Table 1.

The data pertaining to total soluble solids, titrable acidity and ascorbic acid revealed that there were none significant effects of both the factors i.e. nitrogen level and bio fertilizers individually as well as interaction. Although maximum value of total soluble solids $\left(21.23^{\circ}\right.$ Brix $)$, titrable acidity $(0.177 \%)$ and ascorbic acid $(5.17 \mathrm{mg} / 100 \mathrm{~g})$ were found under $\mathrm{D}_{1} \mathrm{~B}_{1} \mathrm{D}_{3} \mathrm{~B}_{5}$ and $\mathrm{D}_{1} \mathrm{~B}_{1}$ interactions, respectively.

Reducing sugars and total content in fruit of banana was found significantly influenced by application of different level of nitrogen fertilizer as well as bio fertilizer individually but interaction effects for both parameters were observed non significant. While, in case of non reducing sugar effect of nitrogen level and bio fertilizers individually as well as interaction were found non significant. Higher reducing sugar $(7.52 \%)$, non reducing sugar $(9.94 \%)$ and total sugar $(17.46 \%)$ were observed under $\mathrm{D}_{1} \mathrm{~B}_{1}$.

The data regarding sugar: acid ratio pulp: peel ratio and shelf life were significantly affected by application of different level of nitrogen fertilizer as well as bio fertilizer individually but interaction effects for these parameters were observed non significant. Although, maximum sugar: acid ratio (130.54), pulp: peel ratio (3.42) and shelf life (11.25 days) were recorded under $\mathrm{D}_{1} \mathrm{~B}_{1}$ interaction.

Application of nitrogen @ 100\% RDN (300 g $\mathrm{N} /$ plant) at different growth stages increases fruit TSS, ascorbic acid, reducing sugars, non reducing sugars, total sugar, sugar: acid ratio, pulp: peel ratio, shelf life and decreases titratable acidity. Higher fruit quality especially reducing sugars, non-reducing sugars, total sugars and sugar: acid ratio can be explained by the role of nitrogen responsible for respirational demand with adequate supply of nutrient synthesis invertase and starch splitting enzymes (Rajendra Prasad, 2000). Whereas TSS, ascorbic acid, pulp: peel ratio and shelf life were found better with $100 \%$ RDN may be related to the manifestation of higher physiological traits.

The plants supplied with nitrogen sources had higher leaf $\mathrm{K}$ content implying that these plants would have absorbed more potassium, which played a better role in carbohydrate synthesis, starch breakdown, synthesis of protein and neutralization of physiologically important organic acids (Bhavidoddi, 2003) resulting in higher quality fruits. The reduction in acidity may be due to the neutralization of organic acids by high $\mathrm{K}^{+}$ level in tissues. These findings are in general agreement with the experimental results reported by El-Noby (2000) and Mohato (2014) in banana.

In the present investigation, when banana plants were treated with Azotobacter 20 $\mathrm{ml} /$ plant along with common application of PSB and KMB two times first at time of planting and second one month after planting recorded lower titratable acidity as well as higher fruit TSS, ascorbic acid, reducing sugars, non reducing sugars, total sugars, sugar: acid ratio, pulp: peel ratio and shelf life.

Quality parameters are improved due to the addition and bio-fertilizer enhanced the biosynthesis and translocation of carbohydrates in fruits. This might be due to production of organic acid which accompanied by the acidification of the organic medium (Kumar, 2013). 
Table.1 Effect of different levels of nitrogen and bio-fertilizers on quality parameters i.e. TSS, titrable acidity, ascorbic acid, reducing sugar, non reducing sugar, total sugar, sugar: acid ratio pulp: peel ratio and shelf life

\begin{tabular}{|c|c|c|c|c|c|c|c|c|c|c|c|c|c|c|c|c|c|c|}
\hline \multicolumn{7}{|c|}{ TSS ( ${ }^{0}$ Brix) } & \multicolumn{6}{|c|}{ Titrable acidity (\%) } & \multicolumn{6}{|c|}{ Ascorbic acid (mg/100 g) } \\
\hline & $\mathbf{B}_{1}$ & $\mathbf{B}_{2}$ & $\mathbf{B}_{3}$ & $\mathbf{B}_{4}$ & $\mathbf{B}_{5}$ & Mean (D) & $\mathbf{B}_{1}$ & $\mathbf{B}_{2}$ & $\mathbf{B}_{3}$ & $\mathbf{B}_{4}$ & $\mathbf{B}_{5}$ & Mean (D) & $\mathbf{B}_{1}$ & $\mathbf{B}_{2}$ & $\mathbf{B}_{3}$ & $\mathbf{B}_{4}$ & $\mathbf{B}_{5}$ & Mean (D) \\
\hline $\mathbf{D}_{1}$ & 21.23 & 20.67 & 20.53 & 20.95 & 19.55 & 20.58 & 0.165 & 0.169 & 0.169 & 0.167 & 0.175 & 0.169 & 5.17 & 5.09 & 5.07 & 5.13 & 4.93 & 5.08 \\
\hline $\mathbf{D}_{2}$ & 21.09 & 20.39 & 20.11 & 20.81 & 19.41 & 20.36 & 0.167 & 0.171 & 0.171 & 0.167 & 0.175 & 0.170 & 5.15 & 5.05 & 5.01 & 5.11 & 4.91 & 5.05 \\
\hline $\mathbf{D}_{3}$ & 20.25 & 19.83 & 19.69 & 19.97 & 19.27 & 19.80 & 0.171 & 0.173 & 0.174 & 0.173 & 0.177 & 0.174 & 5.03 & 4.97 & 4.95 & 4.99 & 4.89 & 4.97 \\
\hline $\operatorname{Mean}(B)$ & 20.85 & 20.29 & 20.11 & 20.57 & 19.41 & & 0.168 & 0.171 & 0.172 & 0.169 & 0.176 & & 5.12 & 5.04 & 5.01 & 5.08 & 4.91 & \\
\hline & \multicolumn{2}{|c|}{ D } & \multicolumn{2}{|c|}{ B } & \multicolumn{2}{|r|}{$\mathbf{D} \times \mathbf{B}$} & \multicolumn{2}{|c|}{ D } & \multicolumn{2}{|c|}{ B } & \multicolumn{2}{|r|}{$\mathbf{D} \times \mathbf{B}$} & \multicolumn{2}{|c|}{ D } & \multicolumn{2}{|c|}{ B } & \multicolumn{2}{|r|}{$\mathbf{D} \times \mathbf{B}$} \\
\hline $\mathrm{SEm} \pm$ & \multicolumn{2}{|c|}{0.25} & \multicolumn{2}{|c|}{0.33} & \multicolumn{2}{|r|}{0.58} & \multicolumn{2}{|c|}{0.001} & \multicolumn{2}{|c|}{0.002} & \multicolumn{2}{|r|}{0.004} & \multicolumn{2}{|c|}{0.050} & \multicolumn{2}{|c|}{0.064} & \multicolumn{2}{|r|}{0.112} \\
\hline CV \% & \multicolumn{6}{|c|}{4.97} & \multicolumn{6}{|c|}{4.34} & \multicolumn{4}{|c|}{$\begin{array}{l}\text { NS } \\
3.84\end{array}$} & & \\
\hline
\end{tabular}

\begin{tabular}{|c|c|c|c|c|c|c|c|c|c|c|c|c|c|c|c|c|c|c|}
\hline \multicolumn{7}{|c|}{ Reducing sugar (\%) } & \multicolumn{6}{|c|}{ Non reducing sugar (\%) } & \multicolumn{6}{|c|}{ Total sugar (\%) } \\
\hline & $\mathbf{B}_{1}$ & $\mathbf{B}_{2}$ & $\mathbf{B}_{3}$ & $\mathbf{B}_{4}$ & $\mathbf{B}_{5}$ & Mean (D) & $\mathbf{B}_{1}$ & $\mathbf{B}_{2}$ & $\mathbf{B}_{3}$ & $\mathbf{B}_{4}$ & $\mathbf{B}_{5}$ & Mean (D) & $\mathbf{B}_{1}$ & $\mathbf{B}_{2}$ & $\mathbf{B}_{3}$ & $\mathbf{B}_{4}$ & $\mathbf{B}_{5}$ & Mean (D) \\
\hline $\mathbf{D}_{1}$ & 7.52 & 7.22 & 7.15 & 7.37 & 6.63 & 7.17 & 9.94 & 9.80 & 9.76 & 9.87 & 9.52 & 9.78 & 17.46 & 17.02 & 16.91 & 17.24 & 16.15 & 16.95 \\
\hline $\mathbf{D}_{2}$ & 7.45 & 7.07 & 6.93 & 7.30 & 6.56 & 7.06 & 9.91 & 9.73 & 9.66 & 9.83 & 9.49 & 9.72 & 17.35 & 16.81 & 16.58 & 17.13 & 16.04 & 16.78 \\
\hline $\mathbf{D}_{3}$ & 7.00 & 6.78 & 6.70 & 6.85 & 6.48 & 6.76 & 9.69 & 9.59 & 9.55 & 9.63 & 9.45 & 9.58 & 16.69 & 16.37 & 16.25 & 16.48 & 15.93 & 16.34 \\
\hline \multirow[t]{2}{*}{ Mean(B) } & 7.32 & 7.02 & 6.92 & 7.17 & 6.55 & & 9.85 & 9.71 & 9.66 & 9.78 & 9.49 & & 17.17 & 16.73 & 16.58 & 16.94 & 16.04 & \\
\hline & \multicolumn{2}{|c|}{ D } & \multicolumn{2}{|c|}{ B } & \multicolumn{2}{|r|}{$\mathbf{D} \times \mathbf{B}$} & \multicolumn{2}{|c|}{ D } & \multicolumn{2}{|c|}{ B } & \multicolumn{2}{|r|}{$\mathbf{D} \times \mathbf{B}$} & \multicolumn{2}{|c|}{ D } & \multicolumn{2}{|c|}{ B } & \multicolumn{2}{|c|}{$\mathbf{D} \times \mathbf{B}$} \\
\hline SEm \pm & \multicolumn{2}{|c|}{0.06} & \multicolumn{2}{|c|}{0.08} & \multicolumn{2}{|r|}{0.14} & \multicolumn{2}{|c|}{0.10} & \multicolumn{2}{|c|}{0.12} & \multicolumn{2}{|r|}{0.22} & \multicolumn{2}{|c|}{0.16} & \multicolumn{2}{|c|}{0.21} & \multicolumn{2}{|c|}{0.37} \\
\hline CD (005) & \multicolumn{2}{|c|}{0.19} & \multicolumn{2}{|c|}{0.24} & \multicolumn{2}{|r|}{ NS } & $\mathrm{N}$ & & \multicolumn{2}{|c|}{ NS } & \multicolumn{2}{|r|}{ NS } & & & \multicolumn{2}{|c|}{0.62} & \multicolumn{2}{|c|}{ NS } \\
\hline CV \% & \multicolumn{6}{|c|}{3.65} & \multicolumn{6}{|c|}{3.99} & \multicolumn{6}{|c|}{3.85} \\
\hline
\end{tabular}

\begin{tabular}{|c|c|c|c|c|c|c|c|c|c|c|c|c|c|c|c|c|c|c|}
\hline \multicolumn{7}{|c|}{ Sugar: acid ratio } & \multicolumn{6}{|c|}{ Pulp: peel ratio } & \multicolumn{6}{|c|}{ Shelf life (days) } \\
\hline & $\mathbf{B}_{1}$ & $\mathbf{B}_{2}$ & $\mathbf{B}_{3}$ & $\mathbf{B}_{4}$ & $\mathbf{B}_{5}$ & Mean (D) & $\mathbf{B}_{1}$ & $\mathbf{B}_{2}$ & $\mathbf{B}_{3}$ & $\mathbf{B}_{4}$ & $\mathbf{B}_{5}$ & Mean (D) & $\mathbf{B}_{1}$ & $\mathbf{B}_{2}$ & $\mathbf{B}_{3}$ & $\mathbf{B}_{4}$ & $\mathbf{B}_{5}$ & Mean (D) \\
\hline $\mathbf{D}_{1}$ & 130.54 & 119.19 & 116.36 & 124.86 & 96.50 & 117.49 & 3.42 & 3.23 & 3.18 & 3.32 & 2.85 & 3.19 & 11.25 & 10.38 & 10.17 & 10.81 & 8.65 & 10.25 \\
\hline $\mathbf{D}_{2}$ & 127.70 & 113.52 & 107.84 & 122.03 & 93.65 & 112.95 & 3.37 & 3.14 & 3.03 & 3.28 & 2.80 & 3.12 & 11.03 & 9.95 & 9.51 & 10.60 & 8.43 & 9.90 \\
\hline $\mathbf{D}_{3}$ & 110.68 & 102.17 & 99.33 & 105.00 & 90.82 & 101.60 & 3.09 & 2.94 & 2.90 & 2.99 & 2.75 & 2.93 & 9.73 & 9.08 & 8.86 & 9.29 & 8.21 & 9.03 \\
\hline \multirow[t]{2}{*}{ Mean(B) } & 122.97 & 111.63 & 107.84 & 117.30 & 93.66 & & 3.29 & 3.10 & 3.04 & 3.20 & 2.80 & & 10.67 & 9.80 & 9.51 & 10.23 & 8.42 & \\
\hline & \multicolumn{2}{|c|}{ D } & \multicolumn{2}{|c|}{ B } & \multicolumn{2}{|r|}{$\mathbf{D} \times \mathbf{B}$} & \multicolumn{2}{|c|}{ D } & \multicolumn{2}{|c|}{ B } & \multicolumn{2}{|r|}{$\mathbf{D} \times \mathbf{B}$} & \multicolumn{2}{|c|}{ D } & \multicolumn{2}{|c|}{ B } & \multicolumn{2}{|r|}{$\mathbf{D} \times \mathbf{B}$} \\
\hline SEm \pm & \multicolumn{2}{|c|}{2.59} & \multicolumn{2}{|c|}{3.34} & \multicolumn{2}{|r|}{5.79} & 0. & & \multicolumn{2}{|c|}{0.04} & \multicolumn{2}{|r|}{0.07} & & & \multicolumn{2}{|c|}{0.27} & \multicolumn{2}{|r|}{0.47} \\
\hline CD (005) & \multicolumn{2}{|c|}{7.50} & \multicolumn{2}{|c|}{9.68} & \multirow{2}{*}{\multicolumn{2}{|c|}{ NS }} & 9. & & 0. & & & $\mathrm{NS}$ & & & & & & NS \\
\hline CV \% & & & 9.0 & & & & \multicolumn{6}{|c|}{3.90} & \multicolumn{4}{|c|}{8.40} & & \\
\hline
\end{tabular}


Hence, the superior quality of banana achieved with Azotobacter may be attributed due to the quick metabolic transformation of starch and pectin into soluble compounds and rapid translocation of sugars from leaves to the developing fruits. Also Azotobacter produces organic acid with organic material present in the soil which accompanied by the acidification of the medium and which ultimately responsible for lesser amount of acidity in fruits. The results obtained in this study are in line with the findings of Kumar and Shanmugavelu (1981), Jeeva et al., (1988) in banana as well as Ram and Rajput (2000) in guava.

Interaction effect between different levels of nitrogen and bio-fertilizers showed non significant result with respect to different quality parameters. Similar results were also noted by Tiwary et al., (1998) in banana. However, slightly improved in quality parameters like TSS, sugars and slightly decreased in titratable acidity was noted by Kanamadi et al., (2004) and El-Moniem and Radwan (2003) in banana.

By considering results of present experiment it can be concluded that individually, both the factors significantly affect various quality parameters i.e. reducing sugar, total sugar, sugar: acid ratio, pulp: peel ratio and shelf life but there is no significant effect of interaction effect on any quality parameters. Maximum results of quality parameters were observed in [D $\mathrm{B}_{1} 100 \% \mathrm{RDN}$, Azotobacter $(20 \mathrm{ml} /$ plant $\left.)\right]$ combination of treatments in compare to all other treatments.

\section{References}

Anonymous, 2018. Horticultural statistics at a glance-2018. Government of India.

Bhavidoddi Rahulkumar, 2003. Effect of organic and inorganic fertilizers on banana $c v$. Rajapuri. M. Sc. Thesis,
University of Agricultural Science,

Dharwad, Karnataka (India)

(Unpublished).

El-Moniem, E. A. A. A. and Radwan, S. M. A., 2003. Response of Willams banana plants to bio fertilization in relation to growth, productivity and fruit quality. Arab Univ. J. Agril. Sci., 11(2):751.

El-Naby, S. K. M. A., 2000. Effect of banana compost as organic manure as growth nutrient status yield and fruit quality of Maghrabi banana, Assiut J. Agric. Sci., 31 (3): 101-114.

Kumar AR and Shanmugavelu., 1981 Studies on the effect of Azotobacter and nitrogen on banana. In: National seminar on Banana Production Technology, Tamil Nadu Agricultural University, Coimbatore. Pp. 125-130.

Kanamadi, V. C.; Shirol, A. M.; Thammaiah, N. and Athani, S. I., 2004. Effect of bio fertilizers on growth and yield of banana $c v$. Rajapuri, Paper presented in National Seminar on Banana Industry, Recent Scenario and Future Strategies at Kalyani. 11-13 June. pp.157-161.

Kumar, S.; Pathak, K. A.; Kishore, K.; Shukla, R.; Solankey S. S. and Singh, D. K., 2013 Effect of bio-fertilizers on biological nitrogen fixation of banana cv. Giant Cavendish. Asian J. Hort., 8 (2): 436-439.

Mahato, S. K.; Suresh, C. P. and Kuna, R. K., 2014. Effects of foliar micronutrient application on growth, yield and fruit quality of plantain cv. Nanderan. Plant Archives. 4: 939-94.

Rajendra Prasad., 2000. Nutrient management stategis for next decade. Fertilizer news April,. 4(4): 13-18, 21-25 and 27-28 (13 page).

Ram, R. T. and Rajput, M. S., 2000. Role of bio fertilizer and manures in production of guava cv. Allahabad safeda. Haryana J. Hort. Sci., 29 (3-4):193194. 
Ranganna, S., 1986. "Manual of Analysis of Fruit and Vegetable Products", Tata Mc Gran Hill Publ. Com. Ltd. New Delhi.

Tiwari, D. K., Abuhasan, M. D. and Chattopadhyay., 1998. Studies on the effect of inoculation with Azotobacter and Azospirillum on growth, yield and quality of banana. Indian J. Agri. Res., 42: 235-240.

\section{How to cite this article:}

Patel, P. R., B. N. Patel, Devraj and Patil, S. J. 2020. Quality of Banana cv. Grand Nain Influenced by Nitrogen and Bio-fertilizers. Int.J.Curr.Microbiol.App.Sci. 9(12): 58-63. doi: https://doi.org/10.20546/ijcmas.2020.912.009 